\title{
SUSTAINABLE MANAGEMENT OF ENERGY SUPPLY INCLUDING THE USE OF WASTE-BASED BIOGAS PROCESSES
}

\author{
Julia Kohl ${ }^{1 *}$, Faika Bozankaya ${ }^{1}$, Silvia Drescher-Hartung ${ }^{1}$, Thorsten Ahrens ${ }^{1}$ and \\ Corinna Klapproth ${ }^{1}$
} ${ }^{1}$ Institute of Biotechnology and Environmental Engineering (IBU), Ostfalia University of Applied Sciences, Salzdahlumer Straße
46/48, 38302 Wolfenbüttel, Germany

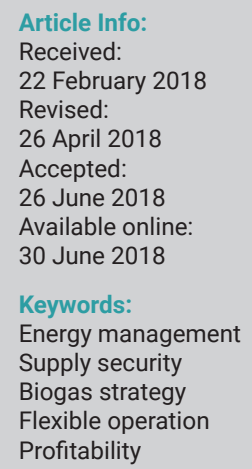

\begin{abstract}
In order to meet the goal of $50 \%$ renewables in the electrical energy mix till 2030 set by the German government the expansion must be continued. One of the biggest problems with the increasing share of renewable energy are the arising fluctuations. In this study it was investigated how the manageability of the biogas production from waste can be used to create a flexible production strategy in order to improve the reliability of a renewable energy supply. The current misbalances between energy demand and supply of wind turbines and PV systems are the basis for this new strategy. The simulation is based on a stand-alone $100 \%$ renewable energy supply of a model town with a population of 1,600 people. In order to investigate the impact of this new biogas management strategy using $100 \%$ renewable energy supply (including wind and solar energy) a simulation tool using MATLAB was designed. Furthermore, to receive preliminary real data regarding flexible biogas production tests were done with a plug-flow digester. Lastly, an economic analysis regarding the profitability was carried out. Simulations in this study have shown that using a flexible and demand adapted biogas management can reduce the required battery capacity by up to $60 \%$. Nonetheless, the combination with feed-in management of wind and solar power has to be further investigated.
\end{abstract}

\section{INTRODUCTION}

While fossil fuel reserves run out, new energy sources are needed for maintaining the energy supply. From 2004 to 2015 the amount of renewable electrical energy in the gross final consumption of electricity has increased from $9.4 \%$ to $30.7 \%$ in Germany (Eurostat, 2017). In order to meet the goal set by the German government of $50 \%$ renewable electrical energy by 2030, the expansion must be continued (Energiekonzept für eine umweltschonende, zuverlässige und bezahlbare Energieversorgung, 2010). One of the biggest problems with increasing the share of renewable energy are the fluctuations of energy production by wind turbines and photovoltaic systems due to changing weather conditions. To avoid sudden drops of voltage, which could lead to brown-outs, and in worse cases to black-outs, conventional energy sources such as flexible gas turbines are currently used as back-up facilities.

Just as low production can cause problems, the over production of energy can lead to an overload of the energy grid. This can result from high wind speeds and increased solar radiation especially in times of low energy demands. To use this surplus in times of lower production rates, the energy needs to be stored, e.g. in battery parks. Not only do short term fluctuations but also long-term fluctuations resulting from seasonal variations have to be balanced.

An alternative renewable energy source that is not prone to fluctuations is biogas, which has a high market share in Germany (16.7\% of electrical renewable energy in 2015 (AGEE-Stat, 2016)). The advantage of biogas is its better manageability compared to wind and solar power as it is independent from weather conditions and thus can be produced continuously.

This study investigated if the manageability of the biogas production can be used to create a flexible production strategy to improve the reliability of a renewable energy supply. In order to investigate the impact of this new biogas management strategy using 100\% renewable energy supply (including wind and solar energy), a simulation tool using MATLAB was designed. To apply these results and collect real data to improve the tool in the future, preliminary tests were carried out so as to find a flexible operation mode protocol. For this reason a pilot scale plug-flow digester and several lab scale fermenters were fed with cow manure and organic waste (food and distillery waste) in 
different ratios and amounts. As a major result, the suitability of waste as basic substrate for the above described scenario was initially proven (according to several process-relevant parameters).

Lastly, an economic analysis was performed to make a statement about the profitability of this new biogas management concept.

\section{ENERGY MANAGEMENT TOOL}

The tool used for the following calculations was developed for the simulation of the energy supply of a model town based on $100 \%$ renewable energy including energy production by a wind turbine, photovoltaic system and an anaerobic digester. As the direct amount of the energy produced by renewable energy plants and the fraction of the energy consumption do not match over the time, strategies to manage resulting fluctuations are required. The most obvious strategy is to use batteries for balancing the mismatches but this requires not only material resources in terms of chemical substances but also financial funds. Another strategy is to adapt the temporary surplus of the energy production of the renewable plants. In this tool both strategies are combined and the impact on the supply security and the required battery capacity is analyzed including feed-in management referring to energy production by anaerobic digesters.

\subsection{Energy production and load data}

The main difference between conventional energy production based on fossil or nuclear power plants and an energy system which depends on $100 \%$ renewable energy is the fluctuating character of wind and solar energy which has to be compensated. These fluctuations can only be taken into account with high-resolution data in time not only for energy production but also for energy consumption which also varies over time.

The development of a strategy to optimize the renewable energy supply with a flexible biogas production and conversion into electricity was carried out for a small supply region representing 1,600 residents. Bigger regions with local differences in weather conditions would require consideration of additional effects which are out of the scope of this study. The load profile of this region has a resolution of one minute and is a synthesis of different load profiles, which were generated with the tool SynPro by the Fraunhofer Institute for Solar Energy Systems.

The Ostfalia University of Applied Sciences owns a small scale wind turbine and a photovoltaic system (Boggasch, 2016). The energy production of these plants is measured with a sampling rate smaller than one second but to match the energy production and consumption data, mean values of one minute were used and a scaling factor was set for aligning the dimensions of energy production and consumption. To consider the inertia of bigger wind turbines, the wind power data was also smoothed by generating mean values of five minutes. As the energy production of wind turbines and photovoltaic systems is weather-dependent, the extracted energy fluctuates heavily. In this paper the annual energy demand is covered from an energy mix shown based on $20 \%$ energy from the wind turbine, $30 \%$ from the photovoltaic plant and 50\% energy from biogas. These shares represent the energy production of the plants divided by the energy consumption, but due to losses of the battery an energy balance of $100 \%$ is not necessarily achieved.

\subsection{Development of a strategy for flexible biogas production}

Biogas is the most flexible and controllable form of energy compared to wind and sun. This advantage is used for reducing differences between energy production and consumption. To quantify long term differences, the monthly balances of an energy supply based on $20 \%$ energy from wind and $30 \%$ energy from sun for the supply region of 1,600 residents were calculated. Figure 1 shows the monthly energy deficits between energy consumption and energy supply without the usage of biogas. The deficits correspond to the shown average power demand which was then adapted by trial and error to enhance the plant utilization. The result of this calculation, as shown in Figure 1, indicates a seasonal pattern of the energy deficit with lower shortfalls in summer time and up to three times bigger deficits in winter.

This seasonal variation was used to generate a demand adapted production of electrical energy from biogas. In this strategy two CHP units are used for the conversion of biogas to electricity. One CHP unit runs on a constant level which equals the energy need in summer and the other one is used to provide the additional energy. To increase the capacity utilization the needed power resulting from the monthly energy deficit was adapted. The total power of both CHP units is shown in Figure 1 by black columns. To enhance the supply security, the power level of the constantly running CHP unit can be adapted if the SOC (state of charge) of the battery is considered critical.

When planning the strategy for the biogas production in the context of this flexible energy production the microbiological limitations have to be taken into account. Each variation of the boundary conditions for the biogas process means a risk for the stability of the biogas production. Therefore, an adapted operating plan for the biogas plant has been developed which includes just two different production levels and two phases for the adjustment in the period of one year.

Two different types of substrates have been chosen for this biogas strategy. One type of substrate is used with a constant amount over the whole year on the level required in summer. The other type is used additionally during the higher production level in winter. The substrate for the constant feed is biowaste to lower the impact for the environment. As additional substrate storable material like corn silage has to be used because the needed amount varies over the year.

\section{IMPACT ANALYSIS OF THE FLEXIBLE BIO- GAS STRATEGY ON SUPPLY SECURITY}

As the aim of the new strategy for biogas production and conversion is the enhancement of the supply securi- 


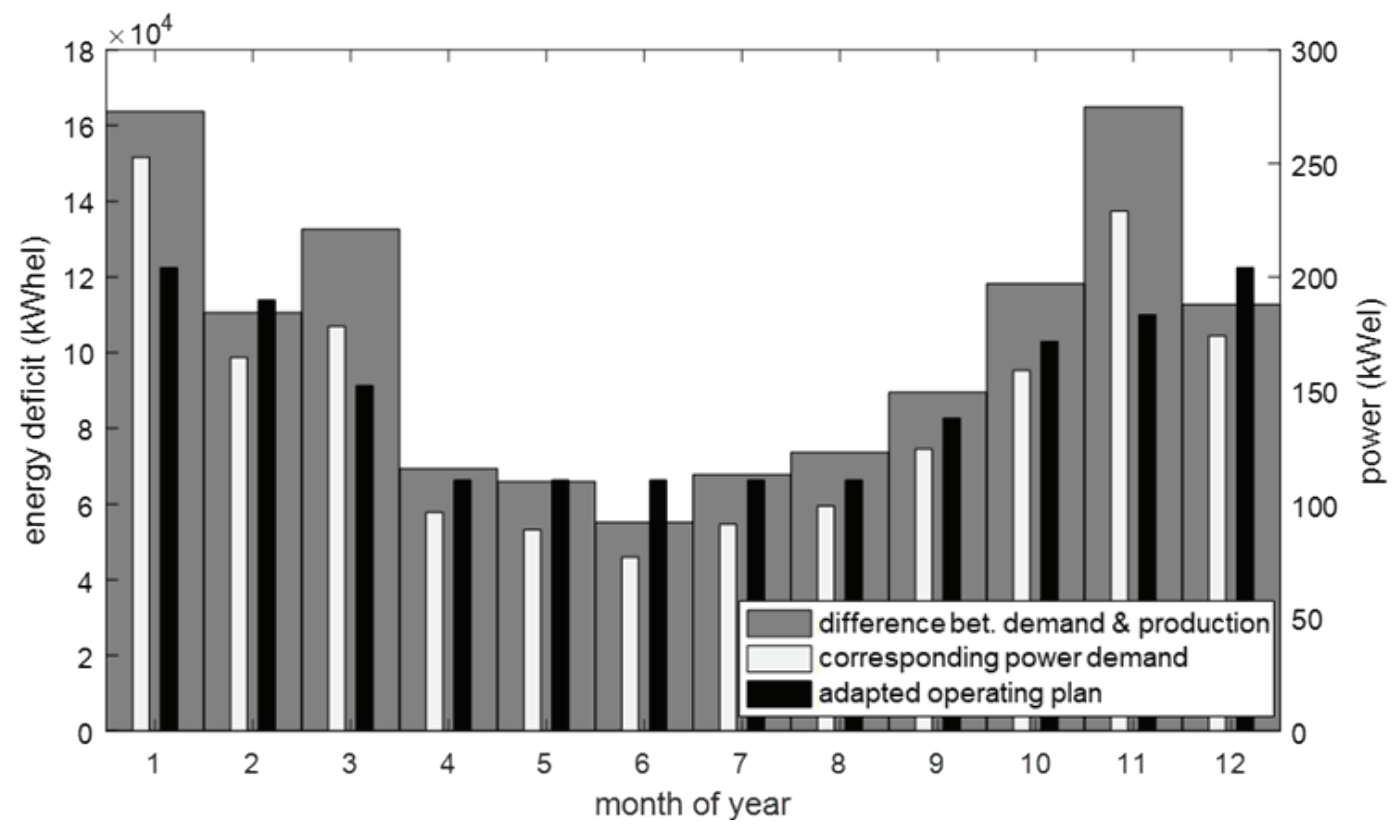

FIGURE 1: Monthly energy deficit between an energy consumption by 1,600 residents and an energy supply based on $20 \%$ energy from wind and $30 \%$ energy from sun in comparison to the resulting power demand and adapted power level.

ty, this impact was analyzed with the developed MATLAB tool by comparing this strategy with a biogas production and conversion on a constant level which equals the annual average of the planned CHP power levels. The chosen parameter for this comparison is the course of the battery SOC over the time because with this device fluctuations between energy production and consumption are balanced. The boundary conditions set for both calculations are the same as shown in Table 1.

Boundary conditions for the comparison of flexible and constant biogas production and conversion

Figure 2 shows the course of the battery SOC in the frame of a flexible biogas production and consumption. The CHP 1 is used to stabilize the SOC in the range between $20 \%$ and $80 \%$ and is adapted if the SOC is out of the range of $30 \%$ to $70 \%$. For this stabilization the power level of the CHP unit can be varied between $+/-30 \%$. In this scenario the minimum SOC is $22 \%$ and the maximum is $72 \%$ which is in the acceptable range of a Lithium-Ion battery (VDE, 2015).

The results presented in Figure 3 are calculated with a constant level of biogas production and conversion. Although the energy balance over the year is just slightly negative, the SOC drops below $20 \%$ and rises above $80 \%$ which damages a Lithium-Ion battery (VDE, 2015). Besides that, the SOC level even drops below $0 \%$ which would result in a breakdown of the energy supply (unlike real batteries the SOC of the simulated battery is not fixed to certain values to clearly show the effects of the operation strategies within a $100 \%$ renewable energy production).

This comparison with this configuration clearly indicates a positive effect of the flexible biogas production and conversion. The result of the simulation involving constant biogas production shows also that bigger battery capacities are necessary to balance the increased range between the minimum and maximum of surplus energy (147 MWh

TABLE 1: Boundary conditions for the comparison of flexible and constant biogas production and conversion.

\begin{tabular}{l|l} 
Parameter & Configuration \\
\hline Relation of energy from wind to sun & $2: 3$ \\
\hline Relation of energy from wind and sun to biogas & $1: 1$ \\
\hline Maximum power of the wind turbine & $750 \mathrm{kWel}$ \\
\hline Maximum power of the photovoltaic system & $600 \mathrm{kWel}$ \\
\hline Battery capacity & 23 days of average consumption $(105 \mathrm{MWh})$ \\
\hline Efficiency of battery (filling / emptying) & $0.9 / 0.9$ \\
\hline Initial SOC of battery & $40 \%$ \\
\hline Efficiency of CHP units (electrical) & 0.4 \\
\hline Calorific value of biogas & $6 \mathrm{kWh} / \mathrm{Nm}$ \\
\hline Planned energy production from biogas per year & $1182 \mathrm{MWhel}$ \\
\hline Energy demand per year & $2103 \mathrm{MWhel}$ (Private households, 1,600 residents) \\
\hline
\end{tabular}




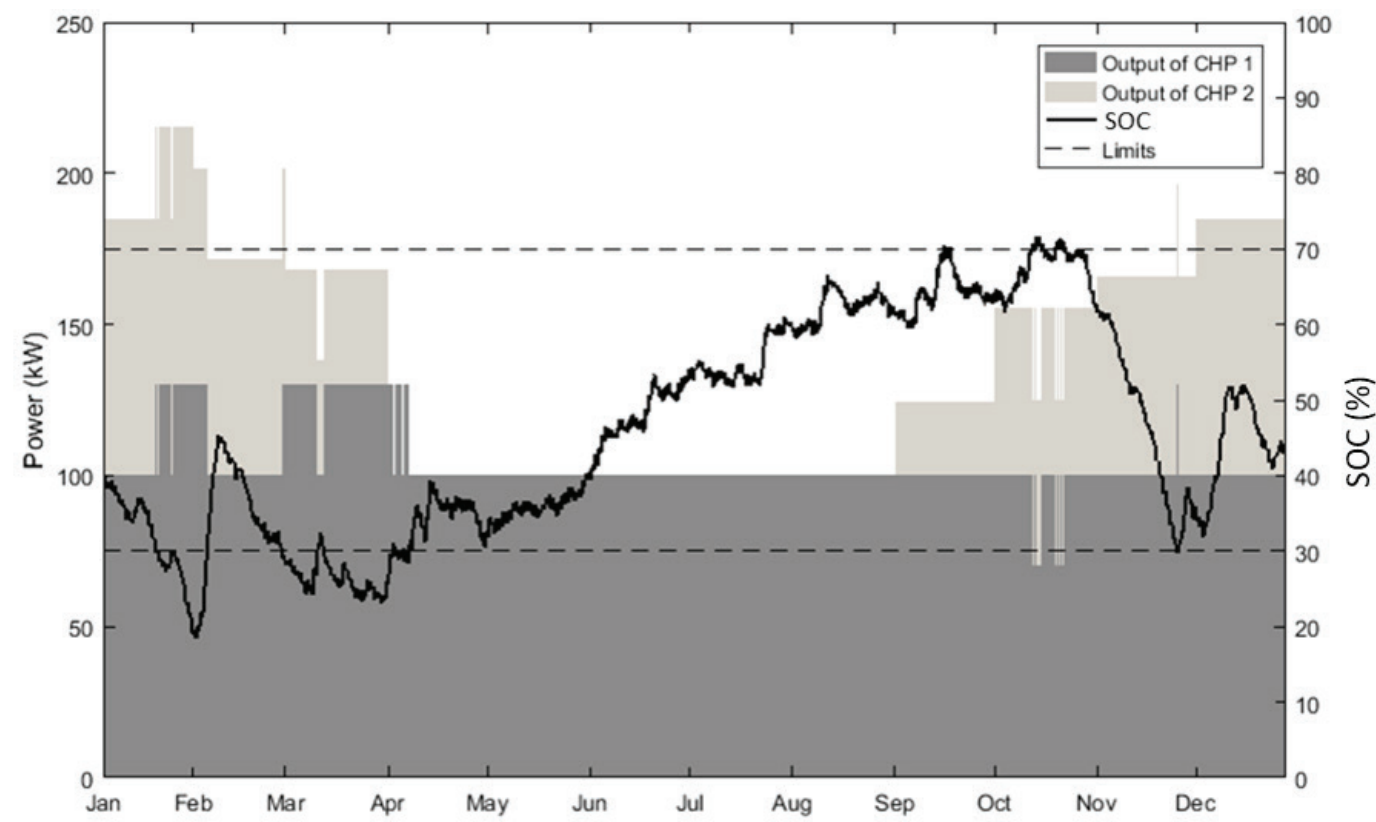

FIGURE 2: Course of the battery SOC and output of the two CHP units with flexible biogas production and conversion (resolution 1 minute).

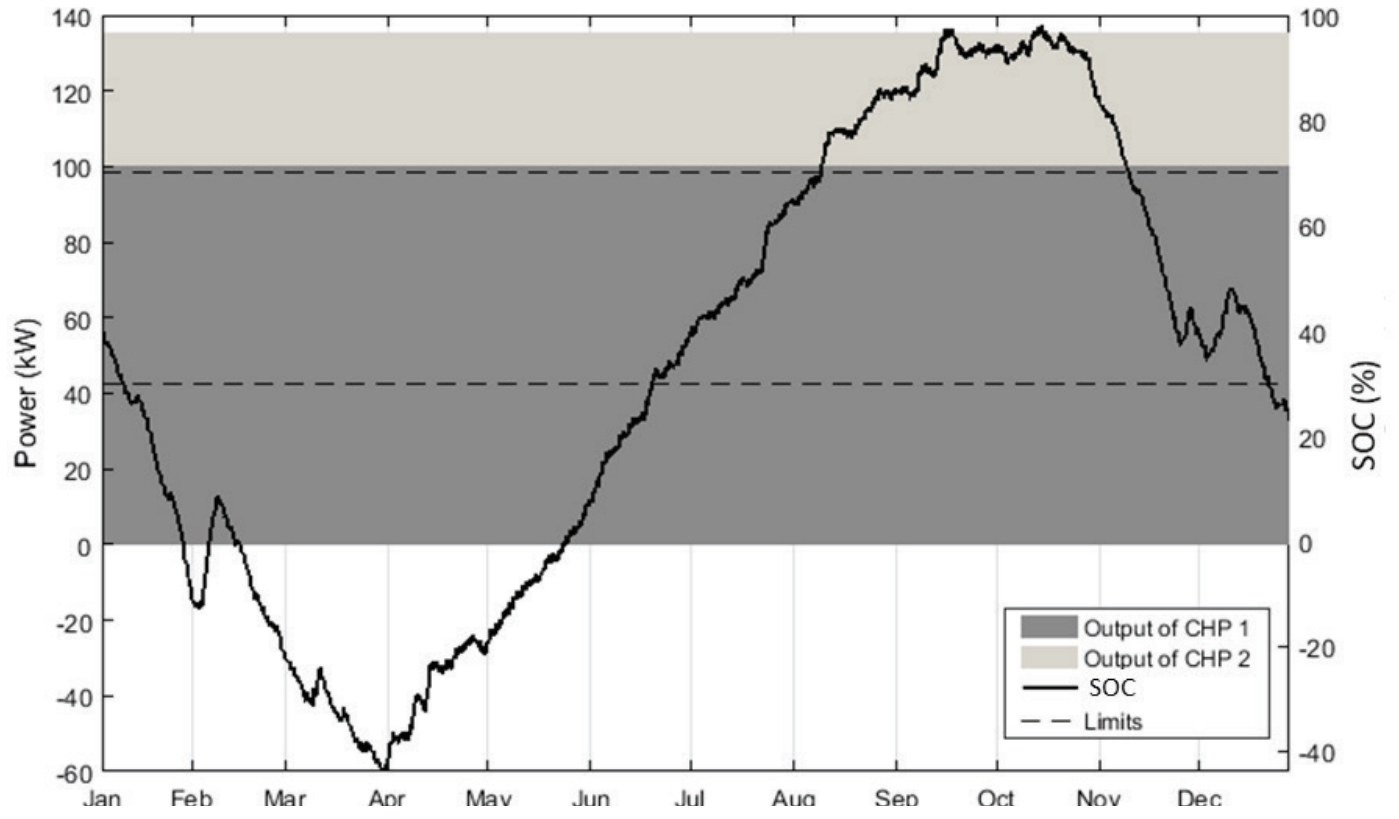

FIGURE 3: Course of the battery SOC and output of the two CHP units with constant biogas production and conversion (resolution 1 minute).

instead of $52.5 \mathrm{MWh}$ ).

Due to the operating range of a Lithium-Ion battery, a capacity of $245 \mathrm{GWh}$ would be necessary to compensate the fluctuations which means an additional demand of $133 \%$.

Another analysis that was done with the developed MATLAB tool is the impact of the variation of the share of biogas energy in the energy mix on the required battery capacity as shown in Figure 4 . The flexible biogas strategy was used for this calculation. The required capacity drops significantly with rising shares of biogas but rises again after the optimum at $60 \%$ biogas in the mix has been reached. This development results on the one hand from the seasonal fluctuations of the deficit between energy consumption and energy production by the wind turbine and photovoltaic system and on the other hand from the biogas strategy based on this fluctuation instead on the fluctuation of the energy consumption. With regard to the dimension of the battery it has to be pointed out that the aim of this study was the analysis of the influence of a new biogas production approach on the battery capacity in a completely renewable energy system.

In order to test and evaluate the practicability of the described strategy, preliminary tests with regards to the flexible biogas production were performed in pilot scale. These are described in the next chapter. 


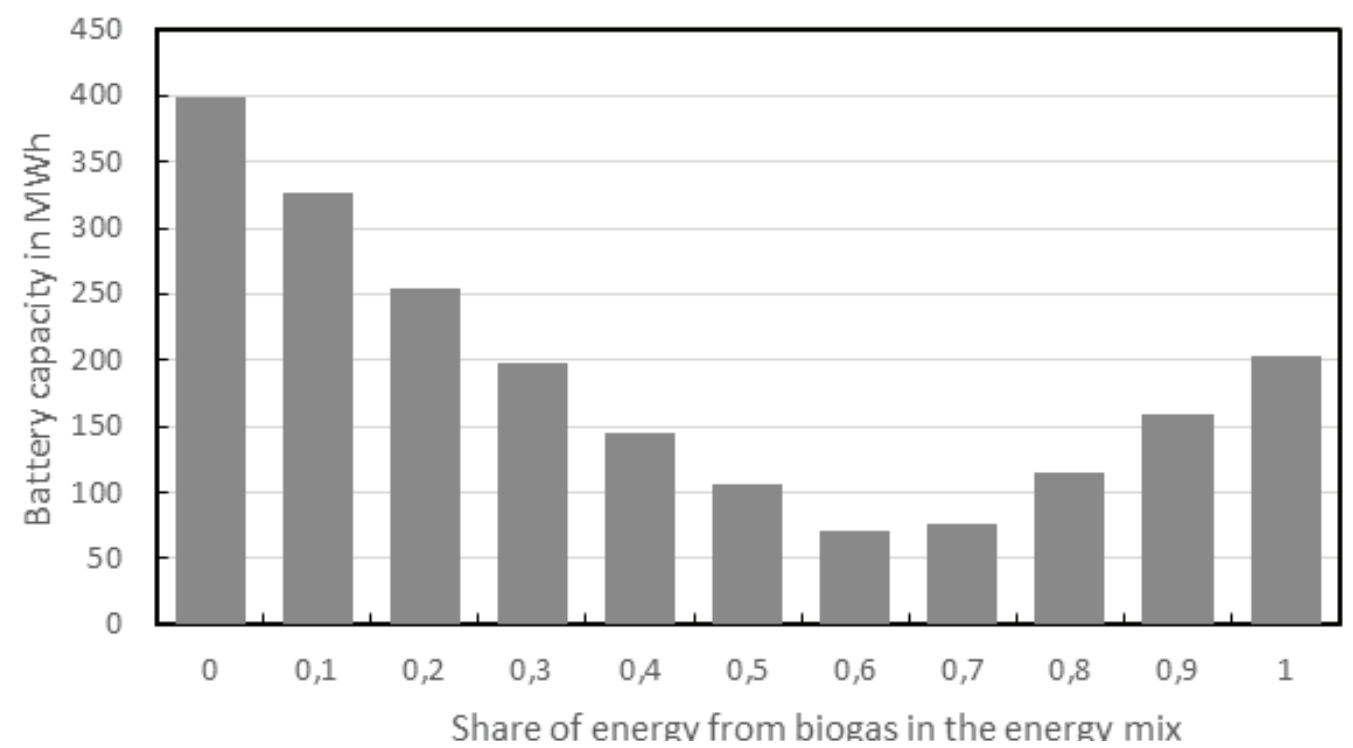

FIGURE 4: Minimum capacity of the Lithium-Ion battery in this scenario with different energy shares from biogas.

\section{FLEXIBLE OPERATION MODE OF ANAERO- BIC DIGESTION}

The concept of a flexible biogas production adapted to the needs of renewable energy systems has to be verified not only on a simulative basis but also in practical systems. Mauky, Jacobi, Liebetrau, and Nelles (2015) showed that in lab scale a flexible daily feeding protocol did not influence the process negatively. As the focus of this study is not on daily fluctuations but rather on changes over a year, it is assumed that increasing or decreasing the biogas production over a month should not have a negative effect. Preliminary results are presented here.

\subsection{Testing of flexible operation mode in a pilot scale plug-flow digester}

The self-designed flow-plug digester Pilot B (Freidank, Daukšys, \& Ahrens, 2013; Freidank, Drescher-Hartung et al., 2013) was used to study the effect of increased feeding over a relatively short time. In short, the reactor had a length of $2850 \mathrm{~mm}$, width of $420 \mathrm{~mm}$, height of $700 \mathrm{~mm}$, and a volume of $500 \mathrm{I}$. Substrate was supplied by a supply hopper and fed in by means of a spiral conveyor. The entry point was slanted at an angle of $30^{\circ}$. An overflow box was built at the end of the reactor with an adjustable overflow level between $450 \mathrm{~mm}$ and $600 \mathrm{~mm}$. The digest was mixed and moved through the digester by 4 horizontally arranged agitators. A ball valve was used for sampling. The produced biogas was collected in 3 air-tight bags with a volume of 250 I each. Using a drum-type gas meter (TG3PP-PP Ritter) the volume was measured. The process was carried out under mesophilic conditions $\left(42^{\circ} \mathrm{C}\right)$. A detailed description can be found in Freidank, Daukšys et al. (2013) and Freidank, Drescher-Hartung et al. (2013).

Substrates were chosen according to their availability within a Lithuanian model region. Cow manure was provided by a local farm, which did not use antibiotics in order to prevent a negative influence on the biogas process. Food waste was collected from three different day care facilities and mainly comprised of starchy foods, vegetables and small amounts of animal protein. Before use it was sterilized in a pressure cooker for $15 \mathrm{~min}$. The distillery waste was provided by $A B$ Biofuture. Algae were collected from the Curonian Lagoon's water surface and its coastal zone. The fresh algae were dried following collection (Freidank, Drescher-Hartung et al., 2013).

At the beginning of the studies the digestion was started out with cow manure and distillery waste. Due to the increase of the water content of the distillery waste, the use was discontinued. After five weeks food waste and algae biomass was added. During the last weeks only cow manure was used as substrate. Overall the amount of substrate was increased over time. The exact composition can be found in Figure 5.

In order to make a statement regarding the process stability VOA/TIC (VOA = volatile organic acids, $\mathrm{TIC}=$ total inorganic carbon) was measured according to Rieger and Weiland (2006).

\subsection{Results of flexible operation mode}

Results clearly showed that changing substrates within a few weeks does not have a negative influence on the process stability (Figure 6). The high VOA/TIC at the beginning showed that the initial amount of substrate was too high. Nonetheless, the value recovered over the next weeks. Indeed VOA/TIC results indicated that the process was underfed toward the end. In further studies the loading rate should be increased. Also, the focus should be more on different organic waste material as these are degraded more quickly which can lead to high VOA/TIC.

Furthermore, lab scale tests were run during the ABOWE project (Freidank, Drescher-Hartung et al., 2013). Substrates used here were cow manure, distillery waste, food waste and algae biomass. The weekly feed started out with $190 \mathrm{~g}$ cow manure which was increased to $1250 \mathrm{~g}$ within two weeks. During week 3 and 8 distillery waste was 


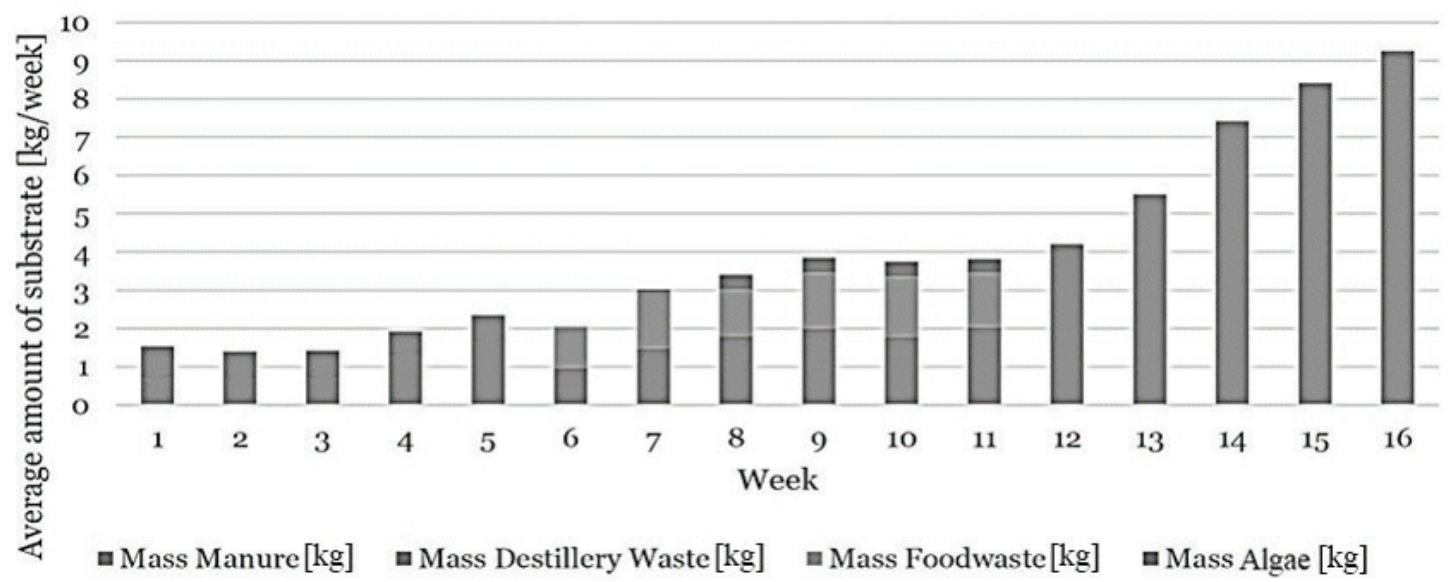

FIGURE 5: Feeding substrate composition of feed during testing of flexible operation mode. Taken with approval from Freidank, Drescher-Hartung et al. (2013)

added with varying quantities. The percentage of distillery waste was increased from approx. $15 \%$ to $50 \%$. Following this, food waste was added as well. Approx. 10\% were added with the rest being equally split between cow manure and distillery waste with a weekly feeding of around $1050 \mathrm{~g}$. This was increased to a feeding amount of $1500 \mathrm{~g}$ from week 9 to 10 . The weekly feeding was then kept at a steady level with equally split amounts between the three substrates between weeks 10 to 13 with a small amount of algae biomass during week 12 and 13. During the last week the weekly feeding amount was slightly reduced to $1350 \mathrm{~g}$.

Results showed that once the methane production started after week 2, the amount slowly increased from approx. $\mathrm{Vn}=0.020 \mathrm{~m}^{3} \mathrm{CH}_{4} /$ week to $\mathrm{Vn}=0.030 \mathrm{~m}^{3} \mathrm{CH}_{4} /$ week within 4 weeks with small dips due to the change of substrate. Nonetheless, this showed that the process was kept stable. Even after adding food waste the process kept stable and the amount of produced biomethane increased to almost $\mathrm{Vn}=0.070 \mathrm{~m}^{3} \mathrm{CH}_{4} /$ week in week 10 , thus showing that the production can be doubled within only one week. The biomethane amount kept on rising, reaching a maximum in week 12 . This clearly indicates a stable process. Following the reduction of feed, the produced amount was reduced. Still, as there were no sudden drops in production rates, it can be said that adding organic waste and changing substrates within weeks does not bring the process to a halt.

These results will have to be applied to the pilot plant Pilot $B$ by changing the previously used feeding strategy to show that this is also possible in a larger scale. Here the aim will also be to see whether the process can be kept stable over a longer period of time as the previous studies stopped after week 14. Furthermore, more organic waste types will be looked at thus creating a broader spectrum of the effects of different substrates on possible optimization strategies.

One of the main concerns of increasing the loading rate too fast and possibly using bio waste with unknown compositions is, besides over-acidification, foam formation. Extensive studies already exist (Lienen et al., 2013; L. Moeller, Goersch, Neuhaus, Zehnsdorf, \& Mueller, 2012; M. Moeller, Görsch, Müller, \& Zehnsdorf, 2012). Preliminary studies of the author and the research group have demonstrated that foaming became a serious problem in lab scale stirring-tank reactors with a load rate of $5.88 \mathrm{~kg}$ oDM $/\left(\mathrm{m}^{3 *} \mathrm{~d}\right)$ (oDM = organic dry matter). This resulted in the foam clogging up the tubing. As the biogas could not escape the reactor the sampling plug was pressed out under strong force.

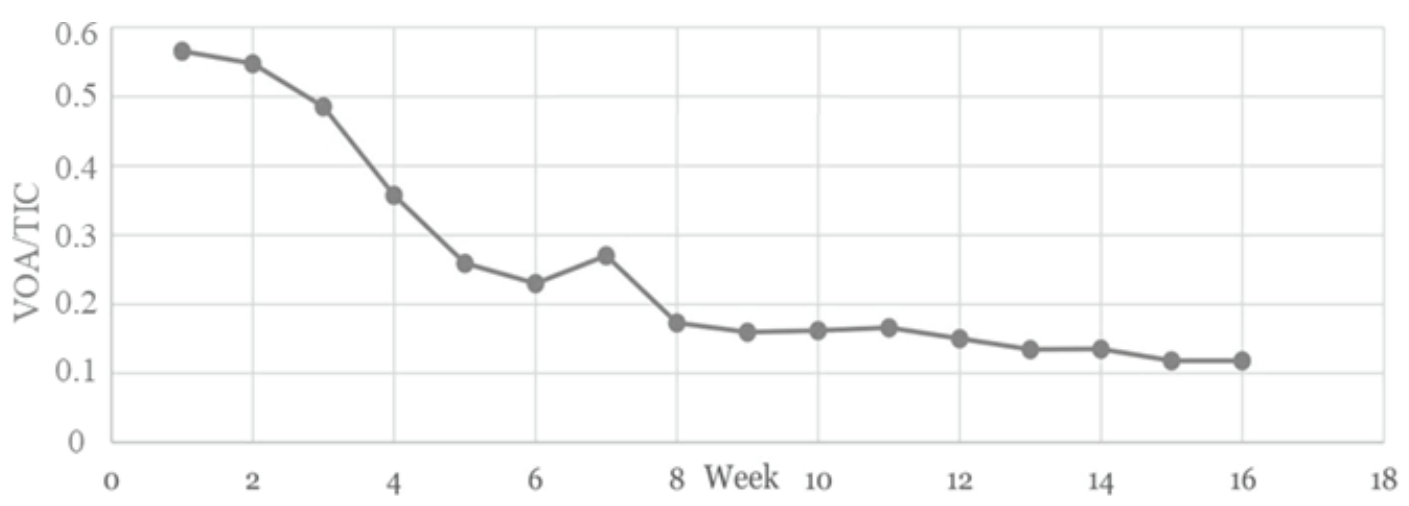

FIGURE 6: Results of VOA/TIC over the course of the investigation. VOA/TIC was high in the beginning due to too high about of starting feed. This recovered over time. Towards the end VOA/TIC values were too low indicating that the system was underfed. Taken with approval from Freidank, Drescher-Hartung et al. (2013) 
In order to keep this from happening while still having high loading rates, anti-foaming solutions have to be found. One new approach will be to look into the effect of condensed tannins with focusing on sainfoin. Positive results on the reduction of bloating has been seen in ruminants (Patra \& Saxena, 2011).

While studying the effects of a flexible operation mode on biomethane production and using the data to feed into the newly developed energy management tool is important, it is just as important to critically evaluate the economic aspects as well. This will be discussed in the next chapter.

\section{CALCULATION OF THE BIOGAS PLANT PROFITABILITY}

Consequently, the profitability of the biogas plant which would be necessary for the realization of the above described scenario has been evaluated. Therefore, the amounts of substrates which were determined in the simulation were used for calculating a simplified economic model of a biogas plant. Also, several important conditions for the operation of such a biogas plant, which have to be taken into account, were examined and determined (e.g. plant system, necessary reinvestments or discount rate), but will not be presented in detail.

In general and in the current situation, the implementation of biogas technology without any public governmental funding and under consideration of a demand based plant operation will result in new challenges concerning the profitability. Implementing biogas technology requires the assessment of many aspects concerning the economic efficiency.

The target parameter is an operative cash flow (OCF), whose calculation is based on the difference between annual revenues on the one hand and annual expenses plus investments on the other hand. For the design of the biogas plant the investment costs and operational plant costs must be considered.

For the calculation of these cash flows a model was developed at Ostfalia University of Applied Sciences, which allows estimating the profitability and economic development over a long time period on the basis of the cumulative discounted cash flow.

However, a detailed calculation and estimate of cash flows is only possible by defining real system models. Therefore, the model includes results of pilot plant operation in certain EU countries, lab tests at Ostfalia University and extensive collection of data (own investigations, literature sources and data from biogas plant operators).

The chosen scenarios and calculated model biogas plant constitute theoretical exemplary situations. The cor- responding assumptions are not meant for a generalized use, as they depend on scenario-specific aspects and were only chosen for these scenarios.

Nevertheless, all variables that influence the profitability can easily be changed and adapted to other scenarios and regions. The resulting impacts can then be illustrated as described above.

For the biogas plant, which has to be implemented into the above-mentioned scenario, the following results concerning the profitability have been calculated (see case-study in Drescher-Hartung, Stasiškienè, and Ahrens (2018)).

With respect to the above described electricity supply scenario a theoretical production of about $250,000 \mathrm{~m}^{3}$ $\mathrm{CH}_{4}$ /year would be possible from a substrate amount of 2,004 tons of biowaste per year (which cannot be stored) and an adapted feeding of corn silage of 680 tons/year.

Table 2 shows the assumptions which were made for the calculation of the profitability.

Assuming that the produced electricity could be sold at a feed-in tariff of $0.247 € / \mathrm{kWhel}$ (which could be the electricity rate currently to be paid by customers in Germany) (Stadtwerke Wolfenbüttel, 2017), a feed-in tariff for heat of $0.03 € /$ kWh (Herbes, Halbherr, \& Braun, 2018), an income from the biowaste collection and utilization of assumed $40 € /$ ton and expenses for the corn silage of assumed 30 $€ /$ ton, the following cash flow would result (Figure 7). For this scenario the payback would be reached after about 6 years.

In comparison to that scenario a second one has been calculated for the case that the electricity producer has to pay grid fees and taxes (then the attainable tariff could be $0.078 € / \mathrm{kWhel}$ ) which means that there are no financial benefits. In that case the payback would not be achieved within the considered period (Drescher-Hartung et al., 2018).

As the results show, the payback period is fundamentally dependent on the earning which is achievable from the substrate and the sale of the electricity. That means the described model is strongly dependent on the tariffs for the electricity, the heat and possibly the digestate as fertilizer. These parameters have to be checked carefully before installing the biogas plant.

In addition, it can be seen from the two scenarios that the operation of the biogas plant is only possible with relevant benefits concerning the electricity feed-in tariff. Therefore, the advantages of the biogas production, which make it possible to balance the electricity production and therefore to provide e.g. the opportunity to reduce necessary energy storage, have to be considered very positive.

TABLE 2: Methane potential and quantities used for the calculation of the profitability

\begin{tabular}{l|lll} 
Substrate & $\begin{array}{l}\text { Methane potential Vn } \\
\left(\mathbf{m}^{3} \mathbf{C H}_{\mathbf{4}} / \mathbf{M g} \text { FM) (FNR, 2017) }\right.\end{array}$ & $\begin{array}{l}\text { Quantity used (Mg/a) }{ }^{\mathbf{2}} \\
\text { (Drescher-Hartung et al., 2018) }\end{array}$ \\
\hline Biowaste & 102 & 2,004 \\
\hline Corn silage & 104 & 680 \\
\hline
\end{tabular}

${ }^{1}$ Calculated with the simulation tool 


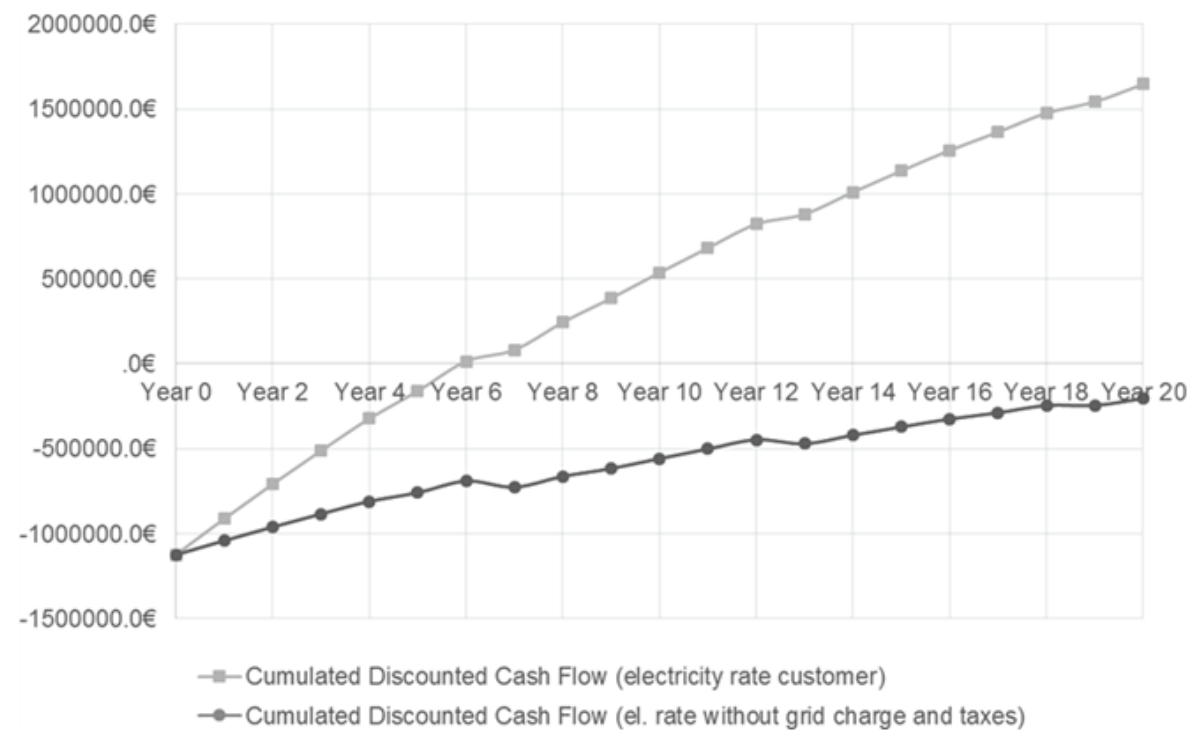

FIGURE 7: Cumulative discounted cash flow of two scenarios (Drescher-Hartung et al., 2018).

\section{CONCLUSION}

Simulations in this study have shown that using a flexible and demand-adapted biogas management can significantly reduce the required battery capacity. Nonetheless, the combination with feed-in management of wind and solar energy has to be investigated. Furthermore, the optimal technical design of storage systems will be taken into account.

In order to apply the results of the simulation to real life scenarios, flexible biogas production was studied. Results showed that increased feed with different compositions of substrates did not have a negative effect on the biogas process stability and resulted in higher biomethane production. Future studies will focus on increasing the loading rate as well as looking at a wider range of substrates where the emphasis should be on different organic wastes. Currently, studies are being carried out looking into the positive effects of sanfoin, as a co-substrate, on the reduction of foaming. This is a known problem that can occur during the biogas production especially when using easily degradable substrates such as biowaste at high loading rates. In order to get a first insight into the economic feasibility an economic analysis was performed. The results have shown that the concept can be profitable. Nonetheless, it is still in a developmental stage.

Although extensive studies are still needed this paper shows that biogas can play an important role in the transition from conventional energy production to a future where the energy demand is completely covered by renewable energy.

\section{References}

AGEE-Stat. (2016). Entwicklung der erneuerbaren Energien in Deutschland im Jahr 2016: Quartalsbericht.

Boggasch, E. (2016). Busgestütztes Energiemanagement eines Verbundes regenerativer Energieanlagen. In E. Bollin, M. Becker, E. Boggasch, M. Fraaß, A. Karbach, P. Ritzenhoff, \& D. Striebel (Eds.), Lehrbuch. Regenerative Energien im Gebäude nutzen: Wärme- und Kälteversorgung, Automation, ausgeführte Beispiele (2nd ed., pp. 234-242). Wiesbaden: Springer Vieweg.
Energiekonzept für eine umweltschonende, zuverlässige und bezahlbare Energieversorgung, Bundesregierung Deutschland 28.10.2010.

Drescher-Hartung, S., Stasiškienė, Ž., \& Ahrens, T. (2018). ENERGY PRODUCTION FROM RESIDUES: ECONOMIC ASSESSMENT OF BIOGAS INSTALLATIONS - DEVELOPMENT OF A CALCULATION TOOL. Detritus. (01), 64-68.

Eurostat. (2017). Share of energy from renewable sources. Retrieved from http://appsso.eurostat.ec.europa.eu/nui/show.do?dataset=nrg_ind_335a\&lang=en

FNR. (2017). Gärsubstrate, Biogasausbeuten. Retrieved from https:// biogas.fnr.de/gewinnung/gaersubstrate/

Freidank, T., Daukšys, V., \& Ahrens, T. (2013). USER GUIDELINE FOR "PILOT B" OPERATION: ABOWE Output Report (No. 0.4.2). Retrieved from Ostfalia University of Applied Sciences website: www.abowe.eu

Freidank, T., Drescher-Hartung, S., Behnsen, A., Anne, O., Daukšys, V., \& Ahrens, T. (2013). MIDTERM OUTPUT REPORT - PILOT B IN LITHUANIA: ABOWE Output Report (No. 0.4.3). Retrieved from Ostfalia University of Applied Sciences website: www.abowe.eu

Herbes, C., Halbherr, V., \& Braun, L. (2018). Preise für die Abgabe von Wärme aus Biogasanlagen an Dritte. Agrarbetrieb, 01, 12-15.

Lienen, T., Kleyböcker, A., Brehmer, M., Kraume, M., Moeller, L., Görsch K., \& Würdemann, H. (2013). Floating layer formation, foaming, and microbial community structure change in full-scale biogas plant due to disruption of mixing and substrate overloading. Energy, Sustainability and Society, 3(1), 20. https://doi.org/10.1186/21920567-3-20

Mauky, E., Jacobi, H.F., Liebetrau, J., \& Nelles, M. (2015). Flexible biogas production for demand-driven energy supply: Feeding strategies and types of substrates. Bioresource Technology : Biomass, Bioenergy, Biowastes, Conversion Technologies, Biotransformation, Production Technologies, 178(1), 262-269.

Moeller, L., Goersch, K, Neuhaus, J., Zehnsdorf, A. \& Mueller, R. (2012). Comparative review of foam formation in biogas plants and ruminant bloat. Energy, Sustainability and Society, 2(1), 12. https://doi. org/10.1186/2192-0567-2-12

Moeller, M., Görsch, K., Müller, R. A., \& Zehnsdorf, A. (2012). Bildung von Schaum in Biogasanlagen und seine Bekämpfung - Erfahrungen aus der Praxis. Landtechnik, 67(2), 110-113.

Patra, A.K., \& Saxena, J. (2011). Exploitation of dietary tannins to improve rumen metabolism and ruminant nutrition. Journal of the Science of Food and Agriculture, 91(1), 24-37. https://doi. org/10.1002/jsfa.4152

Rieger, C., \& Weiland, P. (2006). Prozessstörungen frühzeitig erkennen. BIOGAS Journal, 4, 18-20.

Stadtwerke Wolfenbüttel. (2017). Allgemeine Preise. Retrieved from https://www.stadtwerke-wf.de/strom/allgemeine-preise.html

VDE. (2015). Kompendium: Li-lonen-Batterien: Grundlagen, Bewertungskriterien, Gesetze und Normen. Frankfurt am Main. 